Conference Paper

\title{
Integrating CBS and WBS in Construction Projects by Using Data Analytics
}

\author{
Mik Wanul Khosiin ${ }^{1 *}$, Wei-Chih Wang ${ }^{2}$, Indradi Wijatmiko ${ }^{3}$ \\ ${ }^{1}$ Civil Engineering, Universitas Pembangunan Nasional "Veteran" Surabaya, East Java, Indonesia \\ ${ }^{2}$ Civil Engineering, National Chiao Tung University, Hsinchu City, Taiwan \\ ${ }^{3}$ Civil Engineering, Universitas Brawijaya, Malang, East Java, Indonesia
}

*Corresponding author:

E-mail: mik.wanul.ts@upnjatim.ac.id

\begin{abstract}
In Indonesia, project databases are not well managed, covering hundreds or thousands of cost items and work items from construction projects. This condition becomes more complex when operators are required to integrate between CBS and WBS, which requires extra effort to perform detailed, rush, and accurate grouping. This study attempts to demonstrate the role of data science in managing CBS and WBS through the code system method in the pivot table. The analysis process requires four stages, step 1. data preparation, step 2. item relationship, step 3. code system analysis, and step 4. validation and evaluation. The results showed that the codes applied including A1001-A1003 have CBS and WBS derivatives in a systematic and well-structured manner so that automatically the calculation of the quantity and cost that accompanies each of these items obtains accurate results. This article is expected to provide options for field practitioners to perform data management to be efficient and productive for the continuity of construction projects going forward.
\end{abstract}

Keywords: CBS and WBS, integration, data analytics, code system

\section{Introduction}

The development of infrastructure is a parameter of a country's progress, if the state is able to build all the facilities needed by its people equally, then the country's economy will increase and the country will develop. There are several types of infrastructure such as buildings, roads, water structures, coastal buildings, airports, railway structures, and others. Each type of building has different characteristics, especially in the work items that compose it. An engineer needs to process all data related to these types of work to be able to manage the project well. This activity can support the success of infrastructure project development.

There are two main groups of work items that are very familiar in the project field, namely the work breakdown structure (WBS) and the cost breakdown structure (CBS). Work items are groups that contain detailed project items that must be worked on by field managers according to certain methods and work sequences. While CBS contains items that contain project-specific costs and specifications, cost items are usually found in contract documents or work agreements that can display the total cost of a project. There needs to be an integration between these two groups of items, because the project will not run well if the relationship between CBS and WBS is not well managed.

Moreover, in Indonesia practice, the data management system or integration between CBS and WBS does not work well, so that managers are often overwhelmed in identifying problems when projects experience delays or inefficiencies. Therefore, it is necessary to conduct an evaluation to improve the current system so that it becomes more effective and productive. 


\section{Research Method}

There are hundreds of items or even thousands of items that are applied in a construction project, depending on the size and size of the project and also based on the type of infrastructure built, all of which affect the number of items to be used in the construction process. There are three levels in the design of CBS and there are six levels of reduction of work in the WBS system, the last level is found the integration between CBS and WBS because they have the same work items. The relationship between CBS and WBS is usually identified by the categories many to one, one to many, many to many, or one to one. D13 steel rebar (CBS) work will be distributed in several work locations including sloof beams, columns, beams, and slabs so that the relationship is from one to many. Then there are several cost items consisting of preparatory work, bow plank, cleaning the work location, and excavation work which are applied only in one location, namely the building foundation so that the relationship between CBS and WBS is many to one.

Various obstacles are often encountered regarding the difficulty of integrating CBS and WBS such as poor data records, poor communication between engineers and field managers, the limited ability of practitioners, large amounts of data, dynamic data that needs to be updated regularly, and unavailability system to manage the integration between CBS and WBS. The code system can be applied as a formula for grouping or associating CBS data with WBS so that later a data bank can be obtained which can be used at any time if the same type of project is being built. The code system is part of data science which is tasked with processing large amounts of data and can provide advice to operators such as automating item grouping, calculating quantity, and identifying project costs.

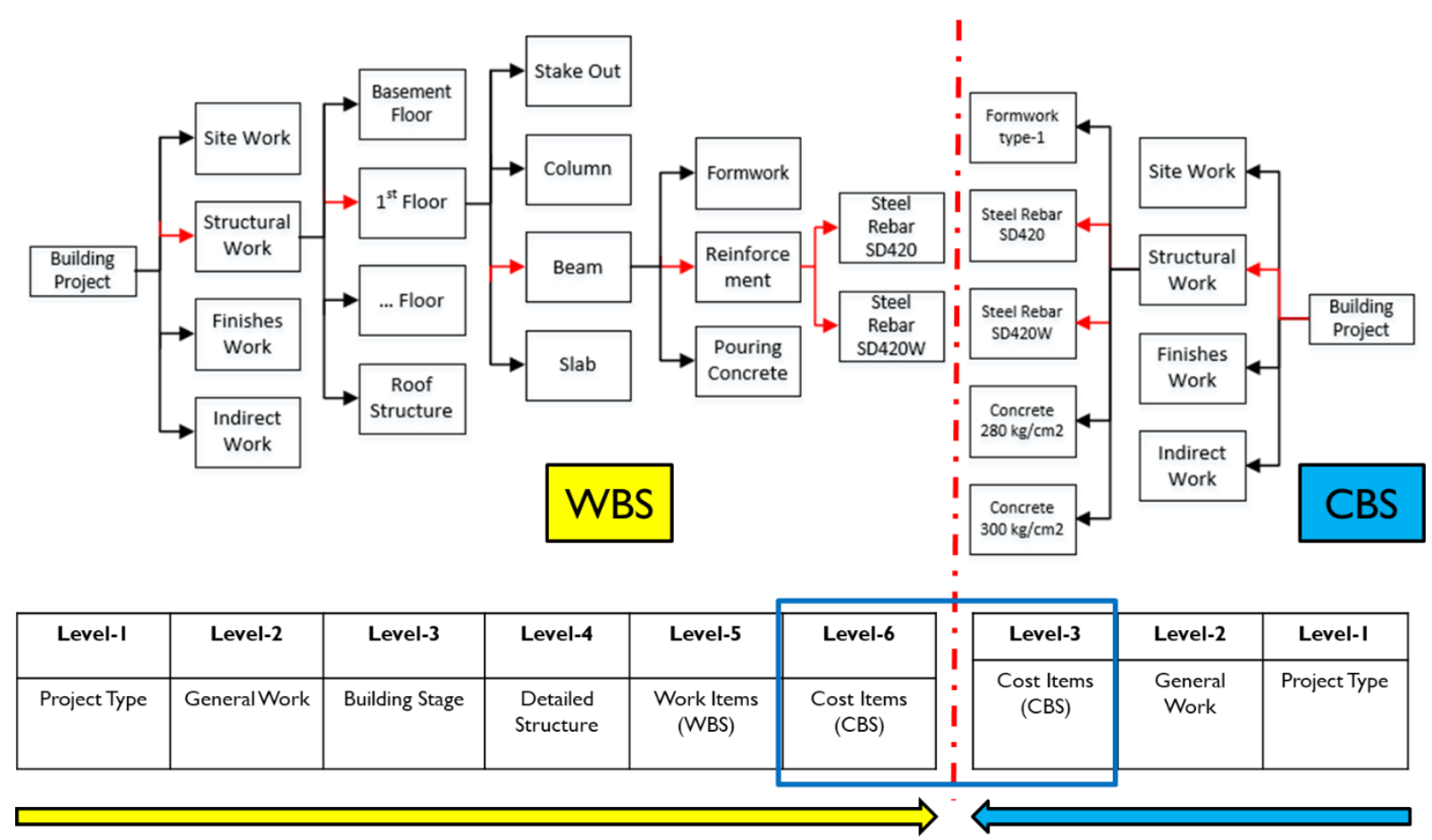

Figure 1. The relationship of CBS and WBS

Four steps need to be considered to ensure that this code system can work to integrate CBS and WBS, namely step 1 . data preparation, step 2. association of work items, step 3. implementation of the code system, step 4. evaluation and validation. Collecting data on all items both CBS and WBS is the first activity that must be done carefully and in detail to avoid repetitive processes in the future. Determining the sequence and work association, namely at level six WBS and level 3 CBS, engineers must be careful at this stage because it will have an impact on the accuracy of providing the code system. The application of the code system uses the Pivot Table method in Microsoft Excel. All data is written based 
on several columns such as code, cost item, work item, quantity, unit, unit price, and cost. Then with the Pivot Table facility, all data that are still mixed will be grouped based on location and function where the code system is the main reference in this process. The final stage is to validate the results of the analysis which must consider the following aspects of the logic of the relationship between work items, volume values, and total costs generated. If there is a discrepancy from the research results, it is necessary to double-check the raw data that was previously made, whether there is an error in data input or the analysis process is not going well.

\section{Results and Discussion}

\section{Data Preparation}

Simple data is used in this study to demonstrate the system code method for the cost item and work item integration process. Based on Table 1, several cost items such as preparation, bow plank, and earthwork use code A1001 and are located in one place, namely, the building foundation (WBS) and are followed by quantity, unit, and cost data, so the relationship between items that occurs here is many (CBS) to one (foundation). The piling work applies code A1002 to the location of the building foundation so that the relationship is one to one. While the single work item SD420 steel rebar is applied in several work locations including sloof, column, and beam, so in this case, the relationship between CBS and WBS is one to many.

Table 1. The raw data of the construction project

$\begin{array}{llllll}\text { Code CBS } & \text { WBS } & \text { QTY Unit HS } & \text { Cost }\end{array}$

\begin{tabular}{lllllll}
\hline A1001 & Preparation & Foundation & 1 & Ls & Rp. 5.000.000 & Rp. 5.000.000 \\
A1001 & Bowplank & Foundation & 50 & $\mathrm{~m}$ & Rp. 96.700 & Rp. 4.835.000 \\
A1001 & Earthwork & Foundation & 240 & M3 & Rp. 408.000 & Rp. 97.920 .000 \\
A1002 & Piling work & Foundation & 100 & $\mathrm{~m}$ & Rp. 768.000 & Rp. 76.880 .000 \\
A1003 & Steel Rebar SD420 & Sloof & 30 & Kg & Rp. 9.000 & Rp. 270.000 \\
A1003 & Steel Rebar SD420 & Column & 55 & Kg & Rp. 9.000 & Rp. 495.000 \\
A1003 & Steel Rebar SD420 & Beam & 22 & Kg & Rp. 9.000 & Rp. 198.000 \\
\hline
\end{tabular}

\section{Item relationship}

Raw data is arranged based on the elements and sequences that occur in the field, the cost items are shown in Table 1 are part of the level 3 items, while those presented in the WBS column are items from level 6 according to Figure 1.Identify the type of relationship between CBS and WBS in the results of the study these are many to one, one to one, and one to many. So that the data in the next column in the form of quantity, unit, unit price, and cost will follow the pattern of the previous three schemes.

\section{Code system analysis}

The advantage of using a Pivot Table in Microsoft Excel is that it can process large amounts of data to be interpreted, summarized, simplified, and presented. This makes it easier for operators to quickly identify which items are involved or affected if progress is mismatched in the field. Engineers can also calculate quickly the items you want to calculate the volume and price for and can display the number of data according to project needs. The application of the code system is written for each cost item that has the same characteristics and functions, in this case, the code A1001, A1002, and A1003 is used to simplify the integration of the work item. Table 2 shows that under code A1003 there is one cost item (steel rebar SD420) that is affiliated with three work items (sloof, beam, and column). 


\begin{tabular}{|c|c|c|c|c|}
\hline Row Labels & $\nabla$ & Sum of QTY & Sum of HS & Sum of COST \\
\hline$\because \mathbf{A} 1001$ & & 291 & $5,504,700$ & $107,755,000$ \\
\hline Eowplank & & 50 & 96,700 & $4,835,000$ \\
\hline Foundation & & 50 & 96,700 & $4,835,000$ \\
\hline$\boxminus$ Earth work & & 240 & 408,000 & $97,920,000$ \\
\hline Foundation & & 240 & 408,000 & $97,920,000$ \\
\hline$\boxminus$ Preparation & & 1 & $5,000,000$ & $5,000,000$ \\
\hline Foundation & & 1 & $5,000,000$ & $5,000,000$ \\
\hline$\boxminus \mathbf{A} 1002$ & & 100 & 768,800 & $76,880,000$ \\
\hline$\boxminus$ Piling work & & 100 & 768,800 & $76,880,000$ \\
\hline Foundation & & 100 & 768,800 & $76,880,000$ \\
\hline$\boxminus \mathbf{A} 1003$ & & 107 & 27,000 & 963,000 \\
\hline$\boxminus$ Steel Rebar SD42 & & 107 & 27,000 & 963,000 \\
\hline Beam & & 22 & 9,000 & 198,000 \\
\hline Column & & 55 & 9,000 & 495,000 \\
\hline Sloof & & 30 & 9,000 & 270,000 \\
\hline Grand Total & & 498 & $6,300,500$ & $185,598,000$ \\
\hline
\end{tabular}

\section{Validation and evaluation}

Based on Table 1, all codes (A1001-A1003) have derivative items (CBS and WBS) that are valid (valid) with the elements applied in the field, this shows that the code system analysis process using the Pivot Table is working well while proving that the method this can help engineers perform good data analysis to achieve better project productivity. With the integration of the cost item and work item, all data components that follow these two items will be automatically summarized and arranged systematically.

\section{Conclusion}

This study was conducted to integrate the cost items and work items that are often found in construction projects with a very large and complex number of items, this is what often becomes an obstacle to identify which items are affected by project delays, so, it is necessary to have study to address this problem. The code system method is applied through the Pivot Table facility in Microsoft Excel to demonstrate the data processing system to be simpler, more systematic, and well-structured. There are four steps used in the analysis process, step 1. preparation of data; step 2. item relationships, step; 3 . code system analysis, step 4 . validation and evaluation.

The data used in this study are representative, using only a few items that might represent actual data in the field. There are three codes used, namely A1001, A1002, and A1003 which are attached to earthwork, piling work, and SD420 steel rebar which is cost items. Then there are also four categories of work items, namely foundation, sloof, column, and beam. All of these items along with the code system were processed using a Pivot Table and the results were quite good, namely that the integration between CBS and WBS could be implemented perfectly, the data display was attractive and easy to understand. The three code systems have CBS and WBS derivatives in a structured manner, as well as the following data components, are processed automatically by the Pivot system to produce maximum results, and the results of this study are expected to contribute to construction practitioners in the field to improve data processing systems. more efficient.

\section{Acknowledgment}

This article was co-authored by Prof. Wei Chih Wang from National Chiao Tung University Taiwan, and Dr. Eng. Indradi Wijatmiko, ST., M.Eng (Prac.) From Brawijaya University Malang 
through research in 2018-2019 and leaning on our master's program thesis at NCTU, Taiwan. Thank you to the supervisors who have guided us in completing this research, and it is hoped that the study will be useful for construction project practitioners wherever they are.

\section{References}

Kim, S. J., Ok, H., \& Kim, T. H. (2017). A study on the integrated process construction expenses management plan in public construction projects using work breakdown structure (WBS). International Journal of Advances in Mechanical and Civil Engineering, 4(6), 1-4.

Monteiro, A., \& Martins, J. P. (2013). A survey on modeling guidelines for quantity takeoff-oriented BIM-based design. Automation in Construction, 35, 238-253.

Wang, K. C., Wang, W. C., Wang, H. H., Hsu, P. Y., Wu, W. H., \& Kung, C. J. (2016). Applying building information modeling to integrate schedule and cost for establishing construction progress curves. Automation in Construction, 72, 397-410. 